\title{
BASC-3 Consistency Index
}

National Cancer Institute

\section{Source}

National Cancer Institute. BASC-3 Consistency Index. NCI Thesaurus. Code C159862.

Flags cases in which child has given different responses to items that usually are answered similarly; a measure of random responding. 